\title{
Primary School Teachers' Perceptions of the Level of Development of Low-Order Cognitive Skills Under the Content and Language Integrated Learning Approach
}

\author{
José-María Campillo-Ferrer* and Pedro Miralles-Martínez \\ Department of Mathematical and Social Sciences Teaching, University of Murcia, Murcia, Spain
}

Content and Language Integrated Learning (CLIL) has become widespread in many countries around the world in an effort to improve learners' communicative competence in a foreign language (FL) and content acquisition in non-language areas (NLA). A successful CLIL programme must integrate the 4Cs, i.e., content, communication,

OPEN ACCESS

Edited by:

Charity M. Dacey,

Felician University, United States

Reviewed by:

María Orcasitas-Vicandi,

University of the Basque Country,

Spain

Blanka Klimova,

University of Hradec Králové, Czechia

${ }^{*}$ Correspondence: José-María Campillo-Ferrer jmcf2@um.es

Specialty section:

This article was submitted to Teacher Education,

a section of the journal

Frontiers in Education

Received: 14 November 2021

Accepted: 21 January 2022

Published: 10 February 2022

Citation:

Campillo-Ferrer J-M and Miralles-Martínez P (2022) Primary School Teachers' Perceptions of the Level of Development of Low-Order

Cognitive Skills Under the Content and Language Integrated

Learning Approach.

Front. Educ. 7:815027.

doi: 10.3389/feduc.2022.815027 cognition and culture. In this study, we focus on the synergies of developing thinking skills by combining language, content and cognition. Specifically, the aim of this study is to examine CLIL teachers' development of low-order cognitive skills (LOTS) in the subjects of Science and Social Science in the first two years of primary education in the Region of Murcia, Spain. For this purpose, we use a mixed method that combines qualitative and quantitative techniques to test the extent to which LOTS are developed within this integrated approach. The results show that most of the cognitive processes promoted by CLIL teachers are those related to fostering understanding among pupils, which sheds light on the strengths and weaknesses of these programmes and on a wide range of related factors on which further reviews are needed.

Keywords: cognition, teaching practice, primary schools, teacher attitudes, mental development

\section{INTRODUCTION}

Content and Language Integrated Learning (CLIL) does not follow traditional foreign language teaching methodologies, and thus can bring about a change in teaching and learning processes, which involves the articulation of guiding principles that provide motivating classroom practice (Pinner, 2013). Thanks to its multifaceted character that rests on the pillars of content, communication, cognition, and culture, this methodological approach departs from the conventional methodological orientations inherent in the concept of foreign language (FL) teaching, not because the lesson is taught in a language that is not the learners' mother tongue, but because its dual-focus objectives involve the simultaneous learning of FL and non-linguistic content within the same teaching practice (Mehisto et al., 2008). For this methodology to be effective, it must challenge learners sufficiently to develop their thinking skills and engage them in the learning process in a cooperative way (Cenoz et al., 2014; Schietroma, 2019). To do this, learners are encouraged to construct their own meaning while learning content in a language that is not their mother tongue. 
In articulating the development of students' thinking skills, many authors point to Bloom's taxonomy, as reviewed by Anderson and Krathwohl (2001), as a useful reference and guide for grouping a wide range of skills into understandable categories according to planned academic purposes. In fact, the range of thinking skills-namely remembering, understanding, applying, analysing, evaluating, and creating - is divided into two different categories: lower order thinking skills (LOTS) for the first three, and higher order thinking skills (HOTS) for the other three. This facilitates learners' progression from concrete to abstract thinking in a gradual manner (Martín-del Pozo and RascónEstébanez, 2021). In this sense, a list of cognitive skills ordered by lower or higher order thinking categories is much more effective than a simple list of skills ordered by relevance, or by topic, because learners can more quickly concentrate on what is asked of them if they know what the cognitive goal of each task is (Campillo-Ferrer et al., 2020). In fact, this hierarchical structure implies progressive mastery of each simple category as an essential prerequisite for moving on to the next more complex category, and this can help learners' self-assessment by providing them with information on the extent to which they have achieved the proposed objectives.

In addition, this taxonomy is also useful for teachers because it has the potential to indicate the extent to which various complex types of cognitive processes are being developed, thus measuring the relevance and appropriateness of specific instructional objectives and activities in a lesson, unit, or course (Krathwohl, 2002). It should also be noted that this hierarchy is flexible enough to allow for overlap between categories, thus favouring the design and implementation of instructional tasks in which the cognitive processes associated with one category may overlap with other processes related to another. This can be exemplified by reading an L2 text, as it may involve the development of decoding and comprehension processes associated with understanding (e.g., interpretation), and the retrieval of relevant knowledge associated with remembering (e.g., recalling). This flexibility can encourage teachers to ensure that there are sufficient opportunities for students to realise the potential of different thinking skills in multifaceted tasks, thus making them predictable (Hanesová, 2014).

If we scrutinise these categories in more detail, we realise that LOTS is central to all primary school subjects in order for learners to develop new ways of thinking and understanding that will enable them to progressively improve their competences, skills and learning outcomes (Tanujaya et al., 2017). This is even more important in CLIL classes, given the cognitive challenges involved in this integrated approach (Brewster, 2009). Children are exposed to subject-specific content that is very often outside their direct experience, which can easily make them feel overwhelmed. For example, in social studies lessons, pupils may find it difficult to explain how the past influences the present, or may even find it very hard to complete other subject-relevant tasks, such as making connections between historical periods in a second or third language (Cambridge ESOL, 2011). In this regard, Mary Coonan (2007) emphasises teachers' need to focus on learners' abilities in order to explore new subject-specific content and foster understanding of information (e.g., by filling in flowcharts, exemplifying or brainstorming). These effective strategies favour the extension of their cognitive scope to further higher-order thinking processes.

In fact, some studies have shed light on the effectiveness and impact of LOTS, such as the study published by AlonsoBelmonte and Fernández-Agüero (2018), which examined the relevance of HOTS and LOTS in primary education in the Spanish Community of Madrid using this approach, and provided evidence that the most recurrent teaching practices are those dedicated to enhancing LOTS, especially those associated with the activation of pupils prior knowledge. In addition, Alcaraz-Mármol (2018) indicated that controlled activities associated with LOTS were implemented more frequently than other more complex activities in bilingual teaching in Spain. Similarly, Barut and Wijaya (2021) concluded that most CLIL practice in Manggarai Timur Regency was aimed at recall and comprehension rather than the development of more complex cognitive categories. Based on the knowledge and information derived from the literature, one can conclude the relevance of exploring how LOTS has been incorporated into CLIL teaching practice in order to foster students' dual-focus learning.

Within the framework of CLIL programmes, this study focusses on primary school teachers' perceptions of their teaching practice in a monolingual context in which non-language areas, namely Science and Social Studies, are taught through a language other than the children's mother tongue. In particular, this research aims to examine the relevance of LOTS in CLIL teachers' everyday practice in the first two years of primary education. More specifically, within the continuum of this dimension of cognitive processes, the study also focuses on which cognitive processes are most developed in CLIL classes. In addition, the relationship between teachers' gender, years of experience and type of training is also analysed, as previous studies have shown the influence of these variables on regular teaching practice (Infante et al., 2009; Klassen and Chiu, 2010; Pawan and Craig, 2011; Alonso-Belmonte, 2014).

\section{RESEARCH METHODS}

\section{Objectives}

The aim of this research is to identify to what extent and how CLIL teachers exploit the potential of LOTS in Science and Social Studies in the first two years of primary education.

RO1: To detail CLIL teachers' views on the development of the cognitive category "Remembering," and, in particular, to examine teachers' different perceptions of the exploitation of the cognitive processes associated with this category according to years of teaching experience, gender and level of CLIL training.

RO2: To obtain information from CLIL teachers on the development of the cognitive category "Understanding" and, in particular, to analyse teachers' perceptions of the exploitation of cognitive processes related to this category according to years of teaching experience, gender and level of CLIL training. 
RO3: To obtain detailed feedback from CLIL teachers on the development of the cognitive category "Apply," and, in particular, to examine teachers' perceptions of the exploitation of cognitive processes associated with this category according to years of teaching experience, gender and level of CLIL training.

In order to achieve these aims, CLIL primary school teachers were consulted using a combined quantitative and qualitative methodology to examine the issues in depth. The participants' responses on both dimensions may provide a broader picture of the educational remains of this educational innovation in order to introduce improvements that will facilitate CLIL educators' teaching practice.

\section{Sample}

In the quantitative study, the sample consisted of 129 CLIL teachers in the Region of Murcia who taught science and social science in the first two years of primary education. In addition to the time dedicated to FL teaching, at least $2 \mathrm{~h}$ per week, depending on the number of NLAs selected in each school, the number of hours per week in English by participants is initially $3.5 \mathrm{~h}$ taught in five classes per week. $76 \%$ per cent of the participants in the quantitative study worked in public schools and $24 \%$ in public schools. Of the CLIL teachers who completed the questionnaire, $78 \%$ had a B2 level of English according to the Common European Framework of Reference for Languages: Learning, Teaching and Assessment (CEFR), while 19\% had a C1 level of English and 3\% a C2 level. Participants' teaching experience ranged from 1 to 30 years, with an average of 11.6 years' experience. Only $16 \%$ of the participants had earned an undergraduate degree in intercultural bilingual education, which meant that their professional training under this approach was acquired after they had completed their university studies. 22\% of the respondents had little or no previous training in CLIL.

Regarding the qualitative study, it should be noted that many previous studies have adopted this methodological approach in an attempt to understand how teachers perceive and make sense of their daily work in different ways and from different perspectives (Papaja, 2014; Roiha, 2019; San Isidro and Lasagabaster, 2019; Turner and Fielding, 2021). In particular, 12 primary school teachers took part in the discussion forum (DF), where they were able to discuss ideas about their teaching practice more freely and openly. 60\% of the participants worked in public schools and $40 \%$ in public schools. Their teaching experience ranged from 7 to 20 years. In terms of L2 proficiency, 66\% had a B2 level, $25 \%$ a C1 level and 9\% a C2 level. The twelve did not have any bilingual qualifications and their CLIL instruction was acquired after they had completed their university education. Three subgroups were held to encourage discussion and exchange of views on current CLIL practice in primary education. The discussions were recorded and transcribed using a series of categories according to the cognitive processes they addressed. The open-ended questions encouraged primary teachers to share their views and feelings about teaching science and social sciences through English as a foreign language to native speakers of Spanish.

\section{Instruments}

The instruments used for this research were a semi-structured questionnaire and a discussion forum, which have been widely adopted in social science studies. As stated by Williamson (2013), they are popular data collection techniques that favour the collection of information from a large number of respondents. The questionnaire was developed ad hoc and validated by a group of experts in the field, who had bilingual teaching experience under this approach and worked at the University of Murcia. Several revisions were necessary to adjust the instrument to the technical requirements suggested by these experts.

The first instrument consisted of several blocks of questions covering the range of items related both to the specific personal and professional profile of the respondents and to the application of LOTS in this context. In particular, the questionnaire included questions related to the frequency of LOTS application: (i) remembering, (ii) understanding, (iii) applying, and also asked participants to rate the frequency with which they fostered the following lower-order cognitive processes: (i) recognising, (ii) remembering, (iii) interpreting, (iv) classifying, (v) explaining, (vi) comparing, (viii) inferring, (ix) summarising, (x) executing and (xi) applying.

The second instrument used was the discussion forum, which is a qualitative data collection technique, usually providing detailed accounts from participants and helping the researcher to better understand critically expressed ideas (Marra et al., 2004). Thus, its main advantages are related to fostering personal interactions, face-to-face discussions and synergetic communication, which enabled participants to exchange their impressions of their everyday bilingual teaching practice without any constraints. The participants' opinions were recorded using the Voice Record application and then transcribed for analysis. We decided to use it because the sample was small and transcription would not be so arduous. The meetings were recorded (total recording time was $140 \mathrm{~min}$ ) and transcribed. In-depth notes were written about the teachers' opinions, identifying possible categories for further coding. Each discussion forum included six questions on how participants implemented their teaching practice from a cognitive perspective and what advantages and disadvantages they identified in this approach. The questions revolved around their experience with this approach and were as follows (a) Are you satisfied with the results of this approach in terms of cognition? (b) Is professional training a key element in CLIL teaching? (c) Do you agree with the sharing of resources to improve your teaching practice? (d) Should there be greater coordination between CLIL teachers? (e) what cognitive processes are most commonly used in CLIL teaching? and (f) what significant improvements and specifications can be suggested to optimise this approach?

\section{Procedures and Data Analysis}

The questionnaire was placed in Google Drive cloud storage and emailed to CLIL teachers. The opinions expressed by the 
respondents were received online after informing the participants of the main objective of this research and the instructions for filling in the questionnaire. Once the information was collected, the steps in the data collection process were as follows: All respondents' questionnaires were classified into different subgroups according to some variables, such as gender, level of CLIL training, number of years of experience or type of school. After reclassifying the respondents' answers, the data were analysed and compared between the subgroups. The frequencies of all items were then measured and the percentages obtained were presented in tables for better visual grouping of the results and more efficient readability.

In addition, non-parametric tests were applied because the collected data did not follow a normal distribution. These tests helped to find statistically significant differences between the groups, which may facilitate the understanding of the key findings of this study. SPSS version 25 was used for the analysis. The degree of reliability of the questionnaire was measured before carrying out the data analysis procedures. It was calculated using Cronbach's alpha and the positive results indicated a high level of reliability $(\alpha=0.94)$.

Regarding the qualitative methodology adopted in this study, the chosen instrument, the discussion forum, was used to collect the information provided in three private meetings with participants lasting $45 \mathrm{~min}$ each. Participants' ideas and opinions were analyzed using qualitative content analysis. Their opinions are presented in the cross-reference tables in the following section, in order to complement the results obtained from the analysis of the questionnaire response data and thus increase the validity of this study.

\section{RESULTS}

This section shows the results of the analysis of the three individual cognitive categories and the opinions expressed by CLIL teachers to foster them in class, which may define the implementation of LOTS in the first two years of primary education in the Region of Murcia.

Specifically, according to the respondents' assessments (RO1), most of the planned activities are geared toward pupils' understanding of NLA content in both public and private schools, with $88 \%$ of teachers in public schools and $92 \%$ in private schools favouring the development of this cognitive category, indicating a high frequency in both educational settings. The other two cognitive categories, applying and remembering, are less developed but with little percentage difference. In terms of gender, both male and female teachers also focus more on promoting understanding than other LOTS (see Table 1).

In terms of participants' CLIL training, some differences have been found, with highly trained teachers focusing more on remembering, compared to the other subgroups who concentrate more on understanding. In terms of respondents' years of teaching experience, there is a clear focus on promoting understanding in CLIL lessons in all subgroups examined (see Table 2). No significant differences were found between the subgroups under study.
TABLE 1 | Development of low-order cognitive skills (LOTS) according to where content and language integrated learning (CLIL) teachers work and their gender.

\begin{tabular}{|c|c|c|c|c|c|c|c|c|}
\hline \multirow{3}{*}{ LOTS } & \multicolumn{4}{|c|}{ Primary school } & \multicolumn{4}{|c|}{ Gender } \\
\hline & \multicolumn{2}{|c|}{ State } & \multicolumn{2}{|c|}{ Private } & \multicolumn{2}{|c|}{ Men } & \multicolumn{2}{|c|}{ Women } \\
\hline & $\mathbf{M}$ & SD & M & SD & $\mathbf{M}$ & SD & $\mathbf{M}$ & SD \\
\hline Remembering & 4.21 & 0.88 & 4.11 & 0.95 & 4.10 & 1.06 & 4.22 & 0.85 \\
\hline Understanding & 4.39 & 0.72 & 4.59 & 0.84 & 4.34 & 0.71 & 4.48 & 0.67 \\
\hline Applying & 4.26 & 0.67 & 4.31 & 0.49 & 4.21 & 0.68 & 4.28 & 0.73 \\
\hline
\end{tabular}

In line with these results, participants in the discussion forums emphasised the relevance of understanding over other thinking skills.

Teacher 9: Well, yes, in my experience with some children, they have better fluency and, above all, understanding.

Teacher 11: That's true. I see that, I mean, from one grade to another, understanding is much higher, communicative intention is much higher as well.

Teacher 12: If my children read a text, most of them understand it very well. If they listen to an oral comprehension, they also understand it very well.

In addition, they were generally satisfied with the cognitive development of learners' understanding of content in FL (DFQuestion a).

Teacher 5: Well, we haven't finished the year yet. I think the level of the students is very good. I think this group is ready.

Teacher 6: We are pleasantly surprised by the level of the students in speaking and even in writing.

In relation to the frequency of use of the cognitive processes associated with each LOTS (RO2, RO3), CLIL teachers agreed on a wide use of the processes with no notable differences between categories (see Figure 1).

Specifically, in relation to the dependent variable "interpreting," related to the cognitive category "understanding," the Mann-Whitney $U$ tests revealed statistically significant differences $(U=1144.50 ; p<0.05)$, with teachers in state schools fostering this lower order cognitive process more frequently than those in public schools. Within the category of "understanding," for the dependent variables "explain," "summarise," statistically significant differences were also found in relation to the type of school where they work $(U=1071 ; p<0.05 ; U=1133.50$; $p<0.05)$. Furthermore, within the category "apply," for the dependent variables "execute" and "implement," some statistically significant differences were identified in relation to the independent variable "type of school where they work" in favour of those working in state schools $(U=1019.50 ; p<0.05$; $U=1043 ; p<0.05)$ (see Table 3).

According to the opinions expressed in the discussion forums, public school teachers are very much involved in promoting cognitive processes related to the cognitive category "apply" which help pupils to acquire and construct new knowledge in a manipulative and cooperative way, although they would like to have more resources for this purpose (DF-Questions c, e, f).

Teacher 6: We want to do really experimental Science, with manipulative things, but there are a lot of things that we don't 
TABLE 2 | Low-order cognitive skills (LOTS) development according to teachers' content and language integrated learning (CLIL) training and years of experience.

\begin{tabular}{|c|c|c|c|c|c|c|c|c|c|c|c|c|c|c|}
\hline \multirow{3}{*}{ LOTS } & \multicolumn{6}{|c|}{ Competence in CLIL } & \multicolumn{8}{|c|}{ Years of experience } \\
\hline & \multicolumn{2}{|c|}{$\mathbf{L}$} & \multicolumn{2}{|c|}{ M } & \multicolumn{2}{|c|}{$\mathbf{H}$} & \multicolumn{2}{|c|}{$<5$} & \multicolumn{2}{|c|}{$5-10$} & \multicolumn{2}{|c|}{$11-20$} & \multicolumn{2}{|c|}{$>20$} \\
\hline & $\mathbf{M}$ & SD & $\mathbf{M}$ & SD & $\mathbf{M}$ & SD & $\mathbf{M}$ & SD & $\mathbf{M}$ & SD & M & SD & $\mathbf{M}$ & SD \\
\hline Remembering & 3.68 & 1.10 & 4.21 & 0.87 & 4.51 & 0.64 & 4.17 & 0.93 & 4.31 & 0.85 & 4.13 & 0.93 & 4.06 & 0.92 \\
\hline Understanding & 4.27 & 0.88 & 4.49 & 0.67 & 4.42 & 0.57 & 4.60 & 0.49 & 4.59 & 0.58 & 4.28 & 0.83 & 4.25 & 0.57 \\
\hline Applying & 4.24 & 0.73 & 4.18 & 0.78 & 4.31 & 0.61 & 4.21 & 0.79 & 4.36 & 0.78 & 4.26 & 0.71 & 4.12 & 0.51 \\
\hline
\end{tabular}

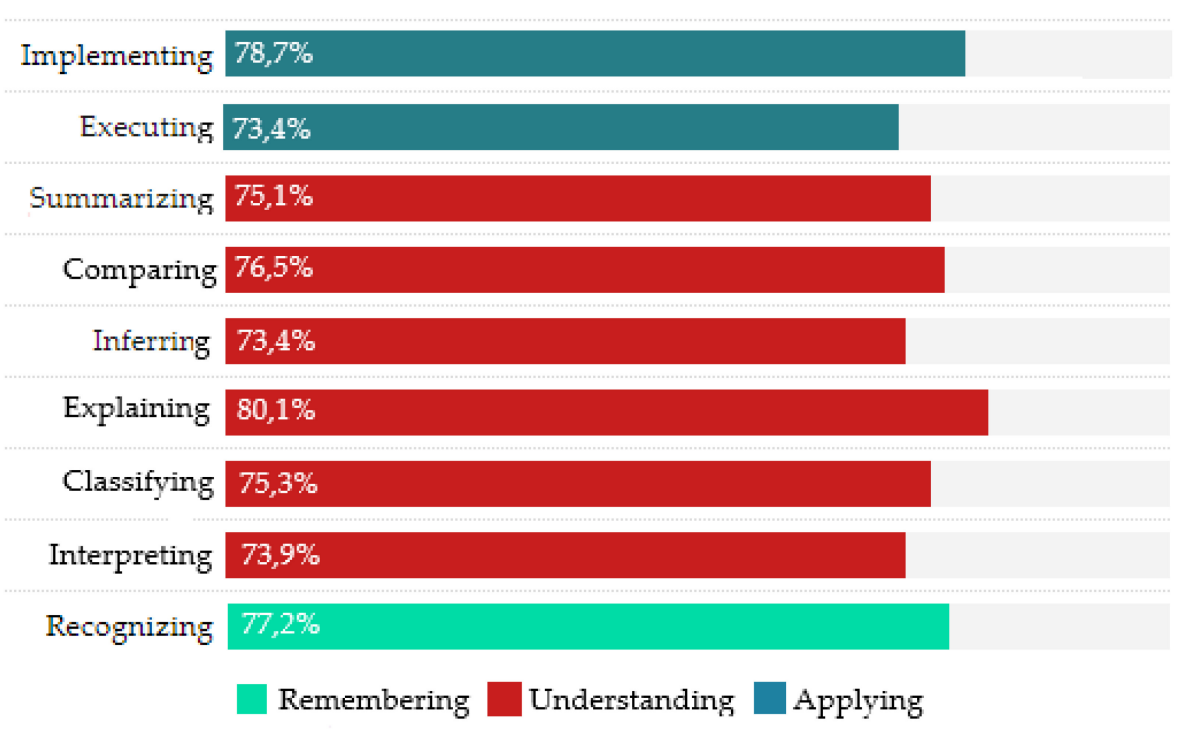

FIGURE 1 | Development of cognitive processes associated with low-order cognitive skills (LOTS).

have at hand for the kids, like a sink or a cooker that has burners, that has lab flasks, test tubes, that has things to do really manipulative Science.

Teacher 5: Yes, that's true.

As for gender as an independent variable, non-parametric tests indicated significant differences in relation to the dependent variables "explaining" and "interpreting" in favour of female teachers $(U=1097 ; p<0.05 ; U=1128 ; p<0.05)$ (see Table 4).

Participants' responses in the discussion forums also revealed their interest in developing these processes in CLIL lessons.

Teacher 4: The oral skills they have are very impressive to people who don't know them at first. We really enjoy listening to them expressing their ideas, communicating with them.

Teacher 5: Yes, it is very noticeable.

Teacher 1: It's very noticeable between the bilingual courses and the ones that are not bilingual. I think it's quite noticeable.

Furthermore, participants attached great importance to coordination between CLIL teachers in order to have a positive impact on pupils' performance and work on NLA content (DFQuestions b and d).

Teacher 2: And also, CLIL has been very useful. The issue of bilingualism has favoured cooperative work much more, from the beginning, for example, my colleague and I went to a training course and from the first day we realised that it is very necessary with bilingualism. You can't just arrive, give a master class and go home, and put on your pyjamas, no, you have to work on a lot of things.

As for the results obtained according to the respondents' level of training in CLIL, significant differences were found in the dependent variable "compare" within the category of "understanding" in favour of those with a higher level of training $(H=9.557 ; p<0.05)$ (see Table 5).

In line with this, some participants expressed the need for better training and coordination (DF-Questions b, d, f).

Teacher 7: I also think that what has happened is that there has been a bit of a rush when it comes to us all becoming bilingual and the teachers have not had time to train. There are teachers who have, because they have trained on their own, but it has all been a bit of a rush and there are some teachers who are very good, but others who are a bit inexperienced.

Teacher 10: It's absolutely true.

As regards the development of cognitive processes in CLIL teaching practice according to the participants' years of experience, the Kruskal-Wallis tests reveal significant differences in "interpreting" (clarifying new content) within the category of "understanding" and "implementing" (using NLA content for different purposes) within the category of "apply." Thus, more experienced teachers carry out more activities to develop these 
TABLE 3 | Non-parametric results of the development of cognitive processes according to the type of school where they work.

\begin{tabular}{|c|c|c|c|c|c|c|}
\hline Thinking skills & Group & $\begin{array}{l}\text { Mean } \\
\text { rank }\end{array}$ & $\begin{array}{l}\text { Sum of } \\
\text { ranks }\end{array}$ & Mann-Whitney U & $\mathbf{Z}$ & p. \\
\hline \multirow[t]{2}{*}{ Implementing } & State & 69.46 & 6877.00 & 1043.00 & -2.60 & $0.009^{\star}$ \\
\hline & Private & 50.27 & 1508.00 & & & \\
\hline \multirow[t]{2}{*}{ Executing } & State & 69.70 & 6900.50 & 1019.50 & -2.80 & $0.005^{\star}$ \\
\hline & Private & 49.48 & 1484.50 & & & \\
\hline \multirow[t]{2}{*}{ Summarizing } & State & 68.55 & 6786.50 & 1133.50 & -2.12 & $0.034^{\star}$ \\
\hline & Private & 53.28 & 1598.50 & & & \\
\hline \multirow[t]{2}{*}{ Comparing } & State & 67.50 & 6484.50 & 1350.50 & -0.252 & 0.548 \\
\hline & Private & 63.35 & 1900.50 & & & \\
\hline \multirow[t]{2}{*}{ Inferring } & State & 65.50 & 6484.50 & 1435.50 & -0.282 & 0.778 \\
\hline & Private & 63.35 & 1900.50 & & & \\
\hline \multirow[t]{2}{*}{ Explaining } & State & 69.18 & 6849.00 & 1071.00 & -2.44 & $0.015^{\star}$ \\
\hline & Private & 51.20 & 1536.00 & & & \\
\hline \multirow[t]{2}{*}{ Classifying } & State & 67.83 & 6715.00 & 1205,00 & -1.66 & 0.097 \\
\hline & Private & 55.67 & 1670.00 & & & \\
\hline \multirow[t]{2}{*}{ Interpreting } & State & 68.44 & 6775.50 & 1144.50 & -1.99 & $0.046^{\star}$ \\
\hline & Private & 53.65 & 1609.50 & & & \\
\hline \multirow[t]{2}{*}{ Recognizing } & State & 68.18 & 6750.00 & 1170.00 & -1.86 & 0.063 \\
\hline & Private & 54.50 & 1635.00 & & & \\
\hline \multicolumn{7}{|l|}{${ }^{*} p<0.05$} \\
\hline \multicolumn{7}{|c|}{$\begin{array}{l}\text { TABLE } 4 \text { | Non-parametric results for the practice of cognitive } \\
\text { processes by gender. }\end{array}$} \\
\hline Thinking skills & Group & $\begin{array}{l}\text { Mean } \\
\text { rank }\end{array}$ & $\begin{array}{l}\text { Sum of } \\
\text { ranks }\end{array}$ & Mann-Whitney U & $\mathbf{Z}$ & p. \\
\hline \multirow[t]{2}{*}{ Implementing } & Men & 59.88 & 1796.50 & 1331.50 & -0.905 & 0.365 \\
\hline & Women & 66.55 & 6588.50 & & & \\
\hline \multirow[t]{2}{*}{ Executing } & Men & 55.72 & 1671.50 & 1206.50 & -1.67 & 0.093 \\
\hline & Women & 67.81 & 6713.50 & & & \\
\hline \multirow[t]{2}{*}{ Summarizing } & Men & 64.42 & 1932.50 & 1467.50 & -0.106 & 0.916 \\
\hline & Women & 65.18 & 6452.50 & & & \\
\hline \multirow[t]{2}{*}{ Comparing } & Men & 62.03 & 1861.00 & 1396.00 & -0.508 & 0.612 \\
\hline & Women & 65.90 & 6524.00 & & & \\
\hline \multirow[t]{2}{*}{ Inferring } & Men & 58.18 & 1745.50 & 1280.50 & -0.1 .20 & 0.227 \\
\hline & Women & 67.07 & 6639.50 & & & \\
\hline \multirow[t]{2}{*}{ Explaining } & Men & 52.07 & 1562.00 & 1097.00 & -2.28 & $0.023^{\star}$ \\
\hline & Women & 68.92 & 6823.00 & & & \\
\hline \multirow[t]{2}{*}{ Classifying } & Men & 54.55 & 1636.50 & 1171.50 & -1.86 & 0.063 \\
\hline & Women & 68.17 & 6748.50 & & & \\
\hline \multirow[t]{2}{*}{ Interpreting } & Men & 53.10 & 1593.00 & 1128.00 & -2.09 & $0.036^{\star}$ \\
\hline & Women & 68.61 & 6792.00 & & & \\
\hline \multirow[t]{2}{*}{ Recognizing } & Men & 56.98 & 1709.50 & 1244.50 & -1.42 & 0.156 \\
\hline & Women & 67.43 & 6675.50 & & & \\
\hline
\end{tabular}

${ }^{*} p<0.05$

processes than less experienced teachers $(H=8.058$; $p<0.05$; $H=7.833 ; p<0.05$ ) (see Table 6).

In relation to this question, some less experienced participants asked for more information on previous teaching methods in order to have a more complete picture of all teaching practices (DF-Questions b, d, f).
TABLE 5 | Non-parametric results of cognitive process practice according to the level of content and language integrated learning (CLIL) teacher training.

\begin{tabular}{|c|c|c|c|c|c|}
\hline $\begin{array}{l}\text { Thinking } \\
\text { skills }\end{array}$ & $\begin{array}{l}\text { CLIL } \\
\text { training }\end{array}$ & Mean rank & Kruskal-Wallis H & gl & p. \\
\hline \multirow[t]{3}{*}{ Implementing } & High & 70.34 & 2.354 & 2 & 0.671 \\
\hline & Mid & 61.02 & & & \\
\hline & Low & 64.48 & & & \\
\hline \multirow[t]{3}{*}{ Executing } & High & 67.64 & 1.560 & 2 & 0.816 \\
\hline & Mid & 67.52 & & & \\
\hline & Low & 58.07 & & & \\
\hline \multirow[t]{3}{*}{ Summarizing } & High & 75.59 & 6.953 & 2 & 0.138 \\
\hline & Mid & 53.44 & & & \\
\hline & Low & 68.72 & & & \\
\hline \multirow[t]{3}{*}{ Comparing } & High & 69.30 & 9.557 & 2 & $0.049^{*}$ \\
\hline & Mid & 57.03 & & & \\
\hline & Low & 66.88 & & & \\
\hline \multirow[t]{3}{*}{ Inferring } & High & 67.96 & 3.468 & 2 & 0.483 \\
\hline & Mid & 56.12 & & & \\
\hline & Low & 67.71 & & & \\
\hline \multirow[t]{3}{*}{ Explaining } & High & 68.68 & 0.812 & 2 & 0.937 \\
\hline & Mid & 65.47 & & & \\
\hline & Low & 65.78 & & & \\
\hline \multirow[t]{3}{*}{ Classifying } & High & 70.25 & 3.754 & 2 & 0.440 \\
\hline & Mid & 69.82 & & & \\
\hline & Low & 57.97 & & & \\
\hline \multirow[t]{3}{*}{ Interpreting } & High & 76.68 & 4.362 & 2 & 0.359 \\
\hline & Mid & 64.32 & & & \\
\hline & Low & 58.90 & & & \\
\hline \multirow[t]{3}{*}{ Recognizing } & High & 61.45 & 2.262 & 2 & 0.688 \\
\hline & Mid & 71.83 & & & \\
\hline & Low & 62.83 & & & \\
\hline
\end{tabular}

Teacher 8: I agree with her. What happens is that I have no point of reference. I have never in my life taught this area in bilingual education.

Teacher 9: We are English specialists, so we have never taught Sciences or Social Studies or other subjects that are taught in bilingual education, so we don't have. what some people say "when I taught Science the children knew more," we can't either.

\section{DISCUSSION}

Content and Language Integrated Learning (CLIL) teaching revolves around certain principles to enhance its scope for the effective development of thinking skills (Ito, 2019; Valverde Caravaca, 2019). In this sense, and taking into account the widespread growth of CLIL programmes and the increasing number of educational policies in this respect, effective teaching skills are essential for providing quality education, considering the importance of adequately promoting meaningful communication and articulating thinking processes for this advancement (Vilkanciené, 2011).

On these issues, significant insights into the development of LOTS have been gained by examining teachers' reflections on 
TABLE 6 | Non-parametric results of the practice of cognitive processes according to teachers' years of experience.

\begin{tabular}{|c|c|c|c|c|c|}
\hline $\begin{array}{l}\text { Thinking } \\
\text { skills }\end{array}$ & $\begin{array}{c}\text { Years of } \\
\text { experience }\end{array}$ & Mean rank & Kruskal-Wallis H & gl & p. \\
\hline \multirow[t]{4}{*}{ Implementing } & $>20$ & 73.94 & 7.833 & 3 & $0.049^{\star}$ \\
\hline & $11-20$ & 73.38 & & & \\
\hline & $5-10$ & 62.66 & & & \\
\hline & $<5$ & 50.89 & & & \\
\hline \multirow[t]{4}{*}{ Executing } & $>20$ & 62.25 & 1.610 & 3 & 0.657 \\
\hline & $11-20$ & 67.72 & & & \\
\hline & $5-10$ & 67.52 & & & \\
\hline & $<5$ & 58.30 & & & \\
\hline \multirow[t]{4}{*}{ Summarizing } & $>20$ & 69.25 & 1.030 & 3 & 0.794 \\
\hline & $11-20$ & 65.70 & & & \\
\hline & $5-10$ & 66.22 & & & \\
\hline & $<5$ & 59.39 & & & \\
\hline \multirow[t]{4}{*}{ Comparing } & $>20$ & 63.63 & 3.461 & 3 & 0.326 \\
\hline & $11-20$ & 73.63 & & & \\
\hline & $5-10$ & 60.33 & & & \\
\hline & $<5$ & 60.48 & & & \\
\hline \multirow[t]{4}{*}{ Inferring } & $>20$ & 63.72 & 2.382 & 3 & 0.497 \\
\hline & $11-20$ & 66.67 & & & \\
\hline & $5-10$ & 69.16 & & & \\
\hline & $<5$ & 56.30 & & & \\
\hline \multirow[t]{4}{*}{ Explaining } & $>20$ & 74.19 & 2.850 & 3 & 0.415 \\
\hline & $11-20$ & 64.87 & & & \\
\hline & $5-10$ & 67.04 & & & \\
\hline & $<5$ & 56.35 & & & \\
\hline \multirow[t]{4}{*}{ Classifying } & $>20$ & 70.19 & 1.552 & 3 & 0.670 \\
\hline & $11-20$ & 66.78 & & & \\
\hline & $5-10$ & 65.74 & & & \\
\hline & $<5$ & 57.98 & & & \\
\hline \multirow[t]{4}{*}{ Interpreting } & $>20$ & 70.81 & 8.058 & 3 & $0.045^{\star}$ \\
\hline & $11-20$ & 62.91 & & & \\
\hline & $5-10$ & 73.77 & & & \\
\hline & $<5$ & 50.11 & & & \\
\hline \multirow[t]{4}{*}{ Recognizing } & $>20$ & 62.06 & 2.771 & 3 & 0.428 \\
\hline & $11-20$ & 66.45 & & & \\
\hline & $5-10$ & 70.01 & & & \\
\hline & $<5$ & 56.19 & & & \\
\hline
\end{tabular}

${ }^{*} p<0.05$.

their CLIL experiences. Firstly, it is possible to assert that thanks to the initiative of educators committed to the implementation of CLIL teaching programmes, it has been possible for LOTS to develop significantly and take on an important role in learners' cognitive progression, as other studies also confirm (AlcarazMármol, 2018; Alonso-Belmonte and Fernández-Agüero, 2018).

It is argued that this initial cognitive development is essential as a means of paving the way for more complex cognitive processes within this approach, which helps to determine the congruence of lesson plans and activities consistent with this basic principle (Puerto and Vázquez, 2016).

Be that as it may, this study has shown that CLIL teachers plan, act and teach thinking skills in very different ways that encourage learners to construct content knowledge in an L2 by activating various cognitive mechanisms and promoting meaningful ways of thinking aimed at triggering content and language learning processes (Martínez-Serrano, 2020).

The reasons for this heterogeneous development are diverse and depend on different factors, such as their experience in these programmes, their CLIL teacher training or the type of school in which they work.

In particular, the impact of the type of school, whether state or private, on CLIL programmes and, more specifically, on the improvement of LOTS has been shown to be a relevant factor in the development of CLIL practices. According to the participants' responses, teachers working in state schools attach more importance to the implementation of practical activities than those in private schools. In fact, practical work is one of the most relevant tools enabling learners to learn procedural knowledge which focuses on the correct performance of actions (Vlasenko et al., 2020). For this reason, teachers in private schools should encourage more practical work in their CLIL classes so that learners are not deprived of some essential thinking skills that provide useful cognitive stimulation and support. A more functional approach, based on learners' needs to communicate effectively and construct meaning in the L2, would be essential for learners to learn more effectively, for example, by carrying out simple experiments in project-type work, detecting correspondences and drawing conclusions from the information presented in group work activities, among other meaningful tasks (Mary Coonan, 2007).

In relation to this issue, CLIL teachers also shared their impressions of the difficulties they face every day in adjusting the space, time and materials available to the methodological requirements associated with this approach (Luanganggoon, 2020). This often meant a lack of opportunity for them to foster the thinking skills essential for practical work, due to the challenge of a broad curriculum to teach and the need to adapt their content and methods accordingly (Martín De Lama, 2015; Chew and Cerbin, 2021). In particular, some of the challenges teachers face in improving students' thinking skills include having sufficient time and knowledge to make content and language accessible, and adapting and designing appropriate materials for their teaching practice within the framework of this time-consuming approach (Moore and Lorenzo, 2015). Obviously, specific contextual factors can affect the effectiveness of teachers' strategies in addressing these challenges. Therefore, the availability of shared cooperative time among educators within their daily practice to reflect on the preparation and delivery of CLIL lessons based on the main CLIL principles and subject-specific curriculum guidelines can substantially enhance the development of these cognitive skills in the classroom (Ball et al., 2016; Hofstadler et al., 2021).

There are also significant differences between participants in the development of other thinking skills in CLIL programmes in primary education according to other variables such as their years of experience in these programmes. In fact, going a step further to understand NLA content more deeply, it has been found that more experienced participants focus more on summarising subject information than less experienced teachers. Another important criteria to be taken into account for this 
cognitive development is teacher training in the CLIL approach (Pérez Cañado, 2018). Although teacher training for CLIL is becoming a key concern for many educational administrations around the world, as it is considered a compulsory part of the education degree programmes of many higher education institutions, a significant percentage of teachers in the Region of Murcia, $22 \%$, embarked on CLIL with little or no experience in CLIL teaching and consequently had to face the different challenges related to this approach almost on their own, while at the same time looking for training opportunities outside their regular working hours, and focusing on cooperative work among other colleagues to bridge the existing gaps in their teaching practice. In a similar study in Spain, Fernández and Halbach (2011) addressed a number of concerns related to CLIL teachers' needs. The research participants clearly highlighted a need for training in teaching science in English (62\%). In relation to this issue, (Cabezuelo Gutiérrez and Fernández Fernández, 2014) also highlighted teachers' need to be trained in methodology and classroom management.

For this reason, in order to prepare them to manage these educational situations more easily and become better CLIL teachers, education administrations should provide more specialised training on how to better adapt their teaching methods to this dual-focus approach (Gondová, 2012). It is therefore essential that teachers receive training on the many ways in which pupils' cognitive learning can be harnessed and extended in CLIL classes. In this respect, training courses aimed at designing appropriate lessons that integrate specific cognitive processes into specific subject tasks may be a crucial step in harnessing the potential of this integrated approach. Accordingly, flexibility, affordability, quality and personalised support are some of the key features that should characterise these training courses so that teachers can have sufficient resources and information with which to practise CLIL cognitive skills before entering the classroom and make the most of their daily work (Pladevall-Ballester, 2015).

Consequently, it seems that there is a need to discuss further the effective practices for addressing LOTS under this approach. The development of these cognitive categories is contextdependent and closely related to the expertise and training of those who use them in specific settings, leading to the need for strong targeting if we want to obtain the most accurate results that can be replicated in similar contexts. Therefore,

\section{REFERENCES}

Alcaraz-Mármol, G. (2018). Trained and Non-Trained Language Teachers on CLIL Methodology: Teachers' Facts and Opinions about the CLIL Approach in the Primary Education Context in Spain. LACLIL 11, 39-64. doi: 10.5294/la-clil. 2018.11.1.3

Alonso-Belmonte, I. (2014). "Genre and professional identity: An exploratory study on the female student teachers' evaluation of experience in EFL," in New insights into gendered discursive practices: Language, gender and identity construction, English in the world series, (Valencia: Servicio de Publicaciones de la Universidad de Valencia), 241-262.

Alonso-Belmonte, I., and Fernández-Agüero, M. (2018). "The C of cognition in CLIL teacher education: Some insights from classroom-based research," in Key further research is needed on the practical delivery of cognitively challenging tasks aimed at optimising CLIL learners' thinking skills (Barut and Wijaya, 2021).

\section{DATA AVAILABILITY STATEMENT}

The raw data supporting the conclusions of this article will be made available by the authors, without undue reservation.

\section{ETHICS STATEMENT}

Ethical review and approval was not required for the study on human participants in accordance with the local legislation and institutional requirements. Written informed consent for participation was not required for this study in accordance with the national legislation and the institutional requirements.

\section{AUTHOR CONTRIBUTIONS}

PM-M determined the research theme, research framework, questionnaire design, data analysis method, and was responsible for the finalization of the manuscript. J-MC-F was responsible for literature collation, questionnaire implementation, and draft writing. PM-M and J-MC-F was responsible for the writing of research hypothesis, data analysis, result discussion, collection, collation of literature, and the collation and analysis of data. Both authors contributed to the article and approved the submitted version.

\section{FUNDING}

The present study was supported by the Spanish Ministry of Science, Innovation and Universities, grant number PGC2018094491-B-C33. This study has been carried out through the funding of project entitled "The geographical and historical thinking of primary education students in the Region of Murcia: an innovative methodological proposal for quality education (20874/PI/18)," funded by Fundación Séneca-Agencia de Ciencia y Tecnología de la Región de Murcia (Spain).

issues in English for specific purposes in higher education, eds Y. Kirkgöz and K. Dikilitaş (Cham: Springer), 305-321. doi: 10.1007/978-3-319-70214-8_17

Anderson, L. W., and Krathwohl, D. R. (2001). A taxonomy for learning, teaching, and assessing: A revision of Bloom's taxonomy of educational objectives. Boston: Addison-Wesley Longman.

Ball, P., Kelly, K., and Clegg, J. (2016). Putting CLIL into Practice: Oxford Handbooks for Language Teachers. Oxford: Oxford University Press.

Barut, M. E., and Wijaya, A. (2021). "Examining Middle School Student's Lower Order Thinking Skill," in 7th International Conference on Research, Implementation, and Education of Mathematics and Sciences (ICRIEMS 2020), (Dordrecht: Atlantis Press).

Brewster, J. (2009). Thinking skills for CLIL. Available online at: http://www.onestopenglish.com/thinking-skills-for-clil/501197.article (accessed October 28, 2021) 
Cabezuelo Gutiérrez, P., and Fernández Fernández, R. (2014). A case study on teacher training needs in the Madrid bilingual project. Latin Am. J. Content Lang. Integrated Learn. 7, 50-70. doi: 10.5294/laclil.2014.7.2.3

Cambridge ESOL (2011). Teaching History through English- a CLIL approach. Cambridge: University of Cambridge.

Campillo-Ferrer, J. M., Miralles-Martínez, P., and Sánchez-Ibáñez, R. (2020). CLIL teachers' views on cognitive development in primary education. Palgrave Commun. 6, 1-7. doi: 10.1057/s41599-020-0480-x

Cenoz, J., Genesee, F., and Gorter, D. (2014). Critical analysis of CLIL: Taking stock and looking forward. Appl. Linguist. 3, 243-417262. doi: 10.1093/applin/amt011

Chew, S. L., and Cerbin, W. J. (2021). The cognitive challenges of effective teaching. J. Economic Educat. 52, 17-40.

Fernández, R., and Halbach, A. (2011). "Analysing the situation of teachers in the Madrid bilingual project after four years of implementation," in Content and foreign language integrated learning, eds Y. Ruiz de Zarobe, J. Sierra, and F. Gallardo del Puerto (Bern: Peter Lang), 241-270.

Gondová, D. (2012). Identifying the Needs of CLIL Teachers at Lower and Upper Secondary Schools. J. Interdiscipl. Philol. 3, 5-22.

Hanesová, D. (2014). Development of critical and creative thinking skills in CLIL. J. Lang. Cult. Educ. 2, 33-51.

Hofstadler, N., Babic, S., Lämmerer, A., Mercer, S., and Oberdorfer, P. (2021). The ecology of CLIL teachers in Austria-an ecological perspective on CLIL teachers' wellbeing. Innovat. Lang. Learn. Teach. 15, 218-232. doi: 10.1080/17501229. 2020.1739050

Infante, D., Benvenuto, G., and Lastrucci, E. (2009). The effects of CLIL from the perspective of experienced teachers. CLIL Pract. 2009, 156-163.

Ito, Y. (2019). The Effectiveness of a CLIL Basketball Lesson: A Case Study of Japanese Junior High School CLIL. Eng. Lang. Teach. 12, 42-54. doi: 10.5539/ elt.v12n11p42

Klassen, R. M., and Chiu, M. M. (2010). Effects on teachers' self-efficacy and job satisfaction: teacher gender, years of experience, and job stress. J. Educ. Psychol. 102, 741-756. doi: 10.1037/a0019237

Krathwohl, D. R. (2002). A revision of Bloom's taxonomy: An overview. Theor. Pract. 41, 212-218. doi: 10.1207/s15430421tip4104_2

Luanganggoon, N. (2020). Content and Language Integrated Learning (CLIL) Teaching Practices in Thailand Higher Education. Asian ESP J. 16, 233-258.

Marra, R. M., Moore, J. L., and Klimczak, A. K. (2004). Content analysis of online discussion forums: A comparative analysis of protocols. Educ. Technol. Res. Dev. 52:23. doi: 10.1007/bf02504837

Martín De Lama, M. T. (2015). Making the match between content and foreign language: A case study on university students' opinions towards CLIL. HLRC 5, 29-46. doi: 10.18870/hlrc.v5i1.232

Martín-del Pozo, M. Á, and Rascón-Estébanez, D. (2021). “Thinking skills in exam models for CLIL primary subjects: Some reflections for teachers," in Teaching language and content in multicultural and multilingual classrooms, (Cham: Palgrave Macmillan), 339-368. doi: 10.1007/978-3-03056615-9_13

Martínez-Serrano, L. M. (2020). “The pedagogical potential of design thinking for CLIL teaching: Creativity, critical thinking, and deep learning," in Handbook of research on bilingual and intercultural education, (Pennsylvania: IGI Global), 427-446. doi: 10.4018/978-1-7998-2588-3.ch018

Mary Coonan, C. (2007). Insider views of the CLIL class through teacher selfobservation-introspection. Int. J. Bilingual Educ. Bilingual. 10, 625-646. doi: 10.2167/beb463.0

Mehisto, P., Marsh, D., and Frigols, M. J. (2008). Uncovering CLIL: Content and language integrated learning in bilingual and multilingual education. London: Macmillan Education.

Moore, P., and Lorenzo, F. (2015). Task-based learning and content and language integrated learning materials design: process and product. Lang. Learn. J. 43, 334-357. doi: 10.1080/09571736.2015.105 3282

Papaja, K. (2014). Focus on CLIL: A qualitative evaluation of content and language integrated learning (CLIL) in Polish secondary education. Cambridge: Cambridge Scholars Publishing.

Pawan, F., and Craig, D. A. (2011). ESL and content area teacher responses to discussions on English language learner instruction. TESOL J. 2, 293-311. doi: 10.5054/tj.2011.259956

Pérez Cañado, M. L. (2018). Innovations and challenges in CLIL teacher training. Theory Pract. 57, 1-10. doi: 10.1080/00405841.2018.149 2238

Pinner, R. (2013). Authenticity of purpose: CLIL as a way to bring meaning and motivation into EFL contexts. Asian EFL J. 15, 138-159.

Pladevall-Ballester, E. (2015). Exploring primary school CLIL perceptions in Catalonia: students', teachers' and parents' opinions and expectations. Int. J. Biling. Educ. Biling 18, 45-59. doi: 10.1080/13670050.2013.874972

Puerto, G. D., and Vázquez, V. P. (2016). Training primary student teachers for CLIL: Innovation through collaboration. Pulso 35-57.

Roiha, A. (2019). Investigating former pupils' experiences and perceptions of CLIL in Finland: A retrospective analysis. Nordic J. Stud. Educat. Policy 5, 92-103. doi: 10.1080/20020317.2019.1586514

San Isidro, X., and Lasagabaster, D. (2019). Monitoring of Teachers' Views on Both CLIL and the Development of Pluriliteracies: A Longitudinal Qualitative Study. English Lang. Teaching 12, 1-16. doi: 10.5539/elt.v12n2p1

Schietroma, E. (2019). Innovative STEM lessons, CLIL and ICT in multicultural classes. J. E-Learn. Knowl. Soc. 15, 183-193.

Tanujaya, B., Mumu, J., and Margono, G. (2017). The Relationship between Higher Order Thinking Skills and Academic Performance of Student in Mathematics Instruction. Int. Educ. Stud. 10, 78-85. doi: 10.5539/ies.v10n11p78

Turner, M., and Fielding, R. (2021). CLIL Teacher training and teachers' choices: exploring planned language use in the Australian context. Lang. Cult. Curric. 34, 224-241. doi: 10.1080/07908318.2020.1792920

Valverde Caravaca, R. (2019). Effective questioning in CLIL classrooms: empowering thinking. ELT J. 73, 367-376. doi: 10.1093/elt/ccz030

Vilkancienè, L. (2011). CLIL in tertiary education: Does it have anything to offer? Kalbø Stud. 2011, 111-116.

Vlasenko, K., Chumak, O., Sitak, I., Kalashnykova, T., \& Achkan, V. (2020). CLIL Method to Increase Students' Motivation in Studying Mathematics at Higher Technical School. Univers. J. Educ. Res. 8, 362-370. doi: 10.13189/ujer.2020. 080205

Williamson, C. (2013). Questionnaires, individual interviews and focus groups. Res. Methods Informat. Syst. Contexts 2013, 349-372.

Conflict of Interest: The authors declare that the research was conducted in the absence of any commercial or financial relationships that could be construed as a potential conflict of interest.

Publisher's Note: All claims expressed in this article are solely those of the authors and do not necessarily represent those of their affiliated organizations, or those of the publisher, the editors and the reviewers. Any product that may be evaluated in this article, or claim that may be made by its manufacturer, is not guaranteed or endorsed by the publisher.

Copyright (c) 2022 Campillo-Ferrer and Miralles-Martínez. This is an open-access article distributed under the terms of the Creative Commons Attribution License (CC BY). The use, distribution or reproduction in other forums is permitted, provided the original author(s) and the copyright owner(s) are credited and that the original publication in this journal is cited, in accordance with accepted academic practice. No use, distribution or reproduction is permitted which does not comply with these terms. 